\title{
RAFALS Y RAALES; RAVALS Y ARRABALES; REALS Y REALES
}

\author{
Por \\ M. ${ }^{a}$ JESUS RUBIERA MATA
}

A la memoria de D. Elias Terés

D. Elías Terés Sádaba será inolvidable para aquéllos que tuvimos la fortuna de ser sus discípulos, no sólo por su magisterio universitario sino también por su entrañable calidad humana

Este artículo, en lo que puede tener de valor, será debido a su magisterio, ya que fue él quien nos dio la clave de la etimología árabe de la voz real en su acepción de "predio rústico», en una ponencia que presentó en el $2 .^{\circ}$ Coloquio Hispano-Tunecino de Estudios Históricos (Madrid-Barcelona, 1972) y que, sin que sepamos la razón, no se publicó en las Actas de dicho Coloquio. Por esta circunstancia $y$ por habernos planteado el tema de la etimología de los arabismos que enunciamos en el título de este artículo, en fecha relativamente reciente, cuando por desgracia D. Elías Terés ya habia fallecido, no hemos podido disponer más que de la memoria para reconstruir los argumentos de su hipótesis, pero el rigor científico de la metodología de D. Elías Terés, bien conocida por quien escribe estas páginas, ya que fue además de discípula, Profesora Adjunta de su Cátedra de Literatura Arábiga en la Universidad Complutense, cerca de quince años, nos ha permitido reconstruir la posible línea de su argumentación.

\section{Rafal/Raal y otros arabismos análogos}

J. Corominas se planteaba el parentesco de una serie de voces de rasgos homófonos en su estudio del término Rehala en su Diccionario Etimológico (1).

Excepto el propio Rehala que aparece en documentos castellanos casi

(1) J. Corominas y J.A. Pascual, Diccionario Critico-Etimológico castellano e hispánico, IV, Madrid, 1981, pp. $853-855$. 
exclusivamente, el resto de las voces homófonas aparecen con gran frecuencia en los documentos medievales de la Corona de Aragón y del Reino de Murcia, con una amplia gama de grafías, tanto en textos latinos, catalanes y castellanos. Intentaremos agruparlos y resumirlos así:

Rahal, forma frecuente en documentos latinos, alternando con raal (Repartimientos de Valencia y Mallorca). También aparece la forma rahallo / rahallo, semejante al rafalla por rehala, de los documentos castellanos.

Rafal, es la forma catalana del rahal latino y que refleja la transformación de las aspiradas árabes $(/ \mathrm{h} / \mathrm{h} / \mathrm{h} / \mathrm{y}$ a veces $/ \mathrm{J} / \mathrm{h}(2)$ en $/ \mathrm{f} / \mathrm{en}$ los arabismos del catalán. Alterna con rahal en los Repartimentos de Valencia y Murcia (como ha señalado A. Galmés de Fuentes, el Repartimento de Murcia fue redactado por el catalán Bernalt Ermengol por lo que sufre una considerable catalanización fonética) (3). Rafal aparece también en la toponimia actual del área del catalán con las formas: rafal, rafalet, rafel y rafol. Como hemos visto antes existe también una forma con palatización de la /l/: Rafallo.

Raal, es fundamentalmente la forma castellana de esta voz que se encuentra en la toponimia del área del castellano. Existen, por ejemplo, un Rafal y un Raal a muy pocos kilómetros de distancia, el primero en Alicante $y$ el segundo en Murcia.

Rafal por otro lado se conserva en el lenguaje vivo, como nombre común en dialecto aragonés, con el significado de "granja; casa o predio en el campo» y en el catalán de Mallorca como «casita de campo, propiedad rústica» y en Murcia también como "granja, grupo de casas de labor» (4).

Real, con la variante Reyal en el repartimiento de Murcia, y que García Soriano en su Vocabulario del dialecto murciano, citado por Corominas, define como «huerto cerrado». Una acepción semejante es mencionada por C. Barceló (5) en Repartimiento de Valencia: ortum sive reales de ceid hualed Alfima.

Todos estos vocablos son considerados por el ilustre etimologista J. Corominas como arabismos procedentes del étimo rah/ en árabe clásico (rahal en dialecto hispano-árabe) con el significado de «lugar donde se hace un alto en el camino», "campamento», "majada, redil», lo cual se adecúa difícilmente a los significados de los arabismos citados, especialmente el de real.

Hay que considerar en primer lugar un aspecto que parece que no se ha tenido en cuenta: los arabismos proceden en su mayor parte del dialecto hispano-árabe y no del árabe clásico -las excepciones pueden restringirse a los tecnicismos de los libros de ciencia- $y$ entre el árabe clásico y

\footnotetext{
(2) F. Corriente, A grammatical sketch of the spanish arabic dialect bundle, Madrid, 1977, 2-1-2.

(3) Dialectologla Mozárabe, Madrid, 1983, p. 164

(4) Corominas, ibidem.

(5) Toponimia aràbica del País Valêncià, Játiva, 1982, pp. 47-48.
} 
el hispano-árabe no sólo hay diferencias fonológicas y morfosintácticas, sino también semánticas (6) y en el caso de rahal, las fuentes lexicográficas del dialecto de Al-Andalus sólo registran una acepción para esta voz, la de majada o redil: caulis en el caso del Vocabulista in Arabico y la de hato en Pedro de Alcalá (7).

Este significado pecuario de rafal viene confirmado por el de otros arabismos procedentes de la misma raíz árabe, como rehala urebañon y rehalf pastor, ambos documentados por Corominas en el artículo citado, lo que indica el campo semántico restringido de esta raíz en hispano-árabe.

\section{Rafal, casa de labor}

La función de los rafales como rediles de ganado vienen también confirmado por su ubicación en terrenos de secano o muntuosa en el repartimiento de Murcia, como ha visto J. Torres Fontes (8), hecho imposible de determinar por ahora a través de la documentación valenciana, a causa de los muchos falsos rafales que aparecen en la misma.

La transformación de un rafal-redil en una cabaña de pastores y de ahí en una casa o varias de tipo rural viene dada por la lógica y se encuentra también en la evolución semántica de otras palabras hispánicas como majada, que de redil pasó a significar casa. Ya en el Repartimento de Murcia se encuentran alusiones a rafales-casas, ya que se habla de que están "derribados», al menos de que se trate de sus posibles cercas.

El rafal-casa pudo pasar fácilmente a ser una casa de labor para recoger aperos o ya una granja. Tenemos una prueba etnológica y arquitectónica de lo que es un rafal, todavía, en la zona de Castellón, a través del estudio realizado por Miguel García Lisón y Arturo Zaragoza, que describen así un rafal:

Els rafals són construccions de planta rectangular, generalment amb murs de pedra seca, o de pedra presa amb argamassa de calc quan es tracta de codols de riu, bolos, de més dificil estabilitat. Sobre aquest murs descansen, a manera de bigues troncs generalment d'olivera que suporten lloses de pedra calcària sobre les quals va una capa de grava fina que remata la coberta. Damunt d'aquesta, sovint creixen herbes que donen als rafals un aspecte característic com si formassen part dels camps de conreu. També poden trobarse solucions amb coberta de teula, a un vessant donades les petites dimensions de la construcció.

Utilizats com refugi rural, el seu espai és unic i el seu mobiliari es rredueix a alguna estaca clavada al mur, un banc d'obra, el cocó o

(6) Corriente, Sketch, op. cit, pp. 151-153.

(7) Hay que tener en cuenta que hato en castellano, además de rebaño, tiene la aceptación de «Sitio que, fuera de las poblaciones, eligen los pastores para comer y dormir durante su esta allí con el ganado».

(8) Repartimiento de la Huerta y Campo de Murcia en el siglo XIII. Murcia, 1971, p. 52. 
armari de paret per a la cantarella, i el pessebre o menjadora per a l'animal, també generalment fabricat en el mateix mur (9).

Como podemos ver los rafals corresponden aún hov en día a su significado hispano-árabe de hato, o cabaña, refugio de pastores.

\section{Los falsos rafals: Ravals/Arrabales y molinos}

En los documentos medievales escritos en el área del catalán aparecen con cierta frecuencia rafals que no corresponden a la etimología de rahal, pero que han dado un resultado homófono debido a la fonética del catalán.

Uno de ellos es raval, en castellano arrabal, barrio.

En esta voz, cuyo étimo es rabad en árabe, la /b/ se transformó en catalán en una labiodental fricativa sonora /v/, cuyo grafema oscilaba entre $/ \mathrm{v} / \mathrm{y} / \mathrm{f} /$. De ahí que al oír raval los escribas pudiesen escribir rafa/ e incluso por hipercultismo rahal. Uno de estos casos, aunque creemos que debe haber muchos más, se encuentra en el Repartimiento de Valencia (10) en el que el topónimo Raval Al-Cadí (El arrabal del cadí) aparece en una ocasión como rafal alcadi ( $n .^{\circ} 321$ ), en un texto que se refiere sin ninguna duda a la ciudad de Valencia y no a una zona rural.

Otra posibilidad de homofonía catalana con la voz rafal de un vocablo de origen muy distinto ya fue señalada por D. Jaime Oliver Asín (11). Se trataría de Rahā, molino, seguido del artículo árabe -L-, que en efecto daría también un rafal. Tenemos un ejemplo de este tipo también en el Repartimiento de Valencia, en un texto que no ofrece lugar a duda de que se trata de un molino: P. Petri, justicia illud casale molendinorum cum // rotis, qui vocatur Rahal Henna. Se trata de un Rahā-I-Hinna, molino de Alheña (12).

\section{Reals/Reales.}

Los reals $y$ reales de los documentos medievales referidos al campo rural, al ser considerados sinónimos de rafal, han producido la consternación de los investigadores, abocados a un callejón sin salida, tanto desde el punto de vista lingüístico como histórico. El propio Corominas dice en el artículo citado: "Además, y por otra parte, "rahal" pudo romanizarse de otra manera -y esto es lo que no se ha visto hasta ahora- reduciéndose a rea/», pero no da ninguna solución a esta romanización.

Creemos que la solución al problema de este arabismo es que no procede de rahal y que no es sinónimo de rafal. La etimología propuesta por

\footnotetext{
(9) Poblament, arquitectura, condicions de la vida doméstica, en Temes d'Etnografia Valenciana, I, Valencia, 1983, p. 154.

(10) Edición A. Ferrando, Valencia, 1978.

(11) El hispano-árabe Alfarnat "los molinos harineros» en la toponimia peninsular, "Al-Andalus», XXII, 1958. pp. $456-459$.

(12) Repartiment, n. ${ }^{\circ} 2266$.
} 
D. Elías Terés es que real procede del étimo árabe riyād, que en el dialecto hispano árabe tenía el significado de jardín, huerta, y no de jardines, huertas como en árabe clásico (13). Su evolución lingüística es también clara, ya que la /d / da / / en las lenguas románicas como ya hemos visto en el caso de rabad = raval/arrabal. Por otro lado se encuentra una forma intermedia, documentada, al menos en el repartimiento de Murcia: el reval de Monteagudo (14).

Los reales, huertos de una riqueza infinitamente superior a los humildes rafales, pasaban en los repartimientos a personas de la más alta categoria, hecho ya señalado en el de Valencia por A. Ferrando (15). El de Monteagudo es otro ejemplo en el de Murcia, ya que pasa a manos de la reina. Con frecuencia, como en este caso, serían realengos, por lo que a veces, tanto por su propietario como por homofonía, se llama a los «Rea//Riyãd’y, Regale, hecho que no señaló amablemente R.I. Burns (16) y que solía existir en ellos un palatium.

\section{Real: campamento.}

Existe otro real cuya etimología todavía es dudosa. Es el real en el sentido de campamento que tan frecuentemente se usaba en la frase «sentar sus reales». Este real está documentado en el Cantar del Mío Cid con la forma reyal que nos hace pensar en un riyãd, mucho más cuando Corominas afirma que no es el campamento de una hueste, sino el albergue de un caballero particular. Podría pensarse que los reves y caballeros cristianos estaban tan acostumbrados a aposentarse en jardines o huertas musulmanas que éstos pasaron a significar albergue o lugar de aposentamiento y finalmente campamento. Pero esto sólo es una hipótesis que precisaría tener más datos para confirmarse.

\section{Consecuencias para la historia de Al-Andalus}

Se ha generalizado la hipótesis del historiador francés P. Guichard de que la estructuración de la sociedad rural del pais valenciano en época árabe se basa en la dicotomía de las alquerías, como lugares habitados por propietarios libres, y los rafales, como propiedades señoriales (17). La base de esta hipótesis, ajena al campo lingüístico como todas las brillantes teorías de P. Guichard, aunque sustentadas en la onomástica y la toponimia árabes, se basa en que los rafales aparecen unidos al nombre de un cargo

(13) Corriente, Sketch, 5-71-16.

(14) Ed. J. Torres Fontes, Madrid, 1960, p. 1

(15) Repartiment, Introducció. XL.

116) Curısamente en un artículo de esta mısma revista de las doctoras Barceló y Labarta, se menciona un realiregale en el que se documenta la etimología de Riyad: Azúcar, "trapigs» y dos textos árabes valencianos, p.

(17) La hipótesis, esbozada en su obra Al-Andalus, estructura antropológica de una sociedad istámica en Occi dente. Madrid, 1976, alcanza categorias de axioma en obras más recientes, como La société rurale valencienne à l'époque musulmane, en Estudis d'Història Agrària, III, 1979, pp. 44-45. 
o de una persona sola, como rafalcadi, rafalwazir, etc., mientras que las alquerías llevan nombres de familia: Beni o de clanes beréberes.

Creemos que esta dicotomía no existe, ya que nada parece más alejado de una propiedad señorial que las pobres cabañas de pastor que son los rafales, muchos de ellos, además son falsos rafales como hemos visto: arrabales de una ciudad, molinos o huertos. Por otro lado ninguno de estos vocablos hace referencia al tipo de propiedad sino a su función específica. Otra cosa es que tanto unos como otros, cabañas de pastor, arrabales, molinos y huertos, sirviesen de punto de referencia a los conquistadores para señalar el número de tahúllas que corresponderían a los nuevos amos. Pero el tipo de reparto y su consiguiente propiedad no forman parte de la historia de Al-Andalus sino de las de los reinos de Aragón y Castilla. 